\title{
Assessment of the endoscopic endonasal approach to the basilar apex region for aneurysm clipping
}

\author{
Ali Tayebi Meybodi, MD, ${ }^{1}$ Arnau Benet, MD, ${ }^{1}$ Vera Vigo, MD, ${ }^{2}$ Roberto Rodriguez Rubio, MD, ${ }^{2}$ \\ Sonia Yousef, BS, ${ }^{2}$ Pooneh Mokhtari, PhD, ${ }^{2}$ Flavia Dones, MD, ${ }^{2}$ Sofia Kakaizada, ${ }^{2}$ and \\ Michael T. Lawton, MD'
}

1'Department of Neurological Surgery, Barrow Neurological Institute, Phoenix, Arizona; and ${ }^{2}$ Skull Base and Cerebrovascular Laboratory, University of California, San Francisco, California

OBJECTIVE The expanded endoscopic endonasal approach (EEA) has shown promising results in treatment of midline skull base lesions. Several case reports exist on the utilization of the EEA for treatment of aneurysms. However, a comparison of this approach with the classic transcranial orbitozygomatic approach to the basilar apex (BAX) region is missing.

The present study summarizes the results of a series of cadaveric surgical simulations for assessment of the EEA to the $\mathrm{BAX}$ region for aneurysm clipping and its comparison with the transcranial orbitozygomatic approach as one of the most common approaches used to treat BAX aneurysms.

METHODS Fifteen cadaveric specimens underwent bilateral orbitozygomatic craniotomies as well as an EEA (first without a pituitary transposition [PT] and then with a PT) to expose the BAX. The following variables were measured, recorded, and compared between the orbitozygomatic approach and the EEA: 1) number of perforating arteries counted on bilateral posterior cerebral arteries (PCAs); 2) exposure and clipping lengths of the PCAs, superior cerebellar arteries (SCAs), and proximal basilar artery; and 3) surgical area of exposure in the BAX region.

RESULTS Except for the proximal basilar artery exposure and clipping, the orbitozygomatic approach provided statistically significantly greater values for vascular exposure and control in the BAX region (i.e., exposure and clipping of ipsilateral and contralateral SCAs and PCAs). The EEA with PT was significantly better in exposing and clipping bilateral PCAs compared to EEA without a PT, but not in terms of other measured variables. The surgical area of exposure and PCA perforator counts were not significantly different between the 3 approaches. The EEA provided better exposure and control if the BAX was located $\geq 4 \mathrm{~mm}$ inferior to the dorsum sellae.

CONCLUSIONS For BAX aneurysms located in the retrosellar area, $\mathrm{PT}$ is usually required to obtain improved exposure and control for the bilateral PCAs. However, the transcranial approach is generally superior to both endoscopic approaches for accessing the BAX region. Considering the superior exposure of the proximal basilar artery obtained with the EEA, it could be a viable option when surgical treatment is considered for a low-lying BAX or mid-basilar trunk aneurysms ( $\geq 4 \mathrm{~mm}$ inferior to dorsum sellae).

https://thejns.org/doi/abs/10.3171/2018.1.JNS172813

KEYWORDS endoscopic transclival approach; interpeduncular cistern; orbitozygomatic approach; pituitary transposition; paraclival internal carotid artery; panhypopituitarism; vascular disorders

$\mathrm{W}$ HILE a significant proportion of basilar apex (BAX) aneurysms are treated with endovascular techniques, 2,20,36 complex BAX aneurysms may require open surgical treatment. . $^{30,33,37}$ On the other hand, despite a wide variety of transcranial approaches proposed for surgical clipping of these lesions, $, 5,9,25,39,44$ the reported complication rates remain relatively high. ${ }^{30,35}$
The endoscopic endonasal approach (EEA) to the skull base is a relatively new and growing technique with promising results in the treatment of many skull base pathologies, $, 11,16,28$ especially after the introduction of the pedicled vascularized nasoseptal flap that proved effective in reducing postoperative CSF leaks. ${ }^{22,23,45}$ The ventral brainstem and the basilar artery may be deemed appealing targets for

ABBREVIATIONS BAX = basilar apex; EEA = endoscopic endonasal approach; ICA = internal carotid artery; PCA = posterior cerebral artery; $\mathrm{PT}=$ pituitary transposition; SCA = superior cerebellar artery. 
an EEA. The retroclival location of the basilar artery and its terminal bifurcation lies in the center of the endoscopic transclival perspective. ${ }^{4,38}$ The endoscopic viewpoint to the basilar artery is orthogonal, and the panoramic upclose view provided by the endoscope may further facilitate maneuvering and manipulating this artery. Furthermore, there is no brain retraction required during the EEA. These factors may lead to the assumption that the EEA is an excellent option for treatment of BAX aneurysms. In fact, there are several previous reports on the treatment of posterior circulation aneurysms, including BAX aneurysms. . $^{10,12,13,19,27,41}$ However, these studies, as well as the few available anatomical studies, have mainly focused on the feasibility of endoscopic surgical access to this region, failing to provide relevant surgical anatomical details and objective evidence on the extent of vascular control over vessels in the BAX region during an EEA. .,7,8,34,42 Furthermore, no study has compared the EEA with any of the common transcranial approaches to the BAX to provide a clear profile of the relative advantages and limitations of the EEA for treating BAX aneurysms.

Through cadaveric surgical dissections, the present study provides an integrative assessment of the EEA for the treatment of BAX aneurysms. To better delineate the role of the EEA in BAX surgery, we have compared the EEA to the BAX region with the orbitozygomatic approach, which is one of the most common transcranial approaches used for the treatment of BAX aneurysms. This cadaveric study was designed not only to assess the anatomical feasibility of the EEA for clipping BAX aneurysms, but also to provide the relevant surgical anatomical details in order to compare its potentials and limitations versus the orbitozygomatic approach.

\section{Methods}

Fifteen cadaveric heads (30 sides) were prepared for dissection using a customized embalming formula ${ }^{1}$ to assess and compare the EEA and orbitozygomatic approaches to the BAX region as described below.

\section{Orbitozygomatic Craniotomy}

Each head was placed in a 3-pin clamp (Mizuho America) and turned $45^{\circ}$ to the contralateral side. The head was slightly extended such that the malar eminence was the highest point on the field. A large, question mark-shaped incision was made $1 \mathrm{~cm}$ below the posterior root of the zygoma and curved posteriorly around the helix. Upon reaching the superior temporal line, the incision turned superiorly and then anteriorly to reach the midline behind the hairline. A large 2-piece orbitozygomatic-pterional craniotomy was then performed using subfascial temporalis muscle dissection as described. ${ }^{21}$ Following dural opening, the sylvian fissure was widely opened using a surgical microscope (Carl Zeiss). Careful arachnoid dissection was then performed to open the basal cisterns to expose the BAX and adjacent structures.

All measurements (transcranial and endoscopic) were performed with the aid of a frameless stereotactic navigation system (Stryker). First, the distance between the $\mathrm{BAX}$ and the upper rim of the dorsum sellae (i.e., BAX height) was measured. If the BAX was located inferior to the dorsum sellae, the distance was recorded as a negative value and vice versa. Next, 4 sets of measurements were obtained, including the following: 1) the number of perforators arising from the $\mathrm{BAX}$ and $\mathrm{P}_{1}$ segments of bilateral posterior cerebral arteries (PCAs), 2) the length of the exposure of the main arterial branches in the region of the BAX, 3) the possibility of safely placing a temporary aneurysm clip on each of the main arterial branches in the region of the BAX, and 4) the surgical area of the exposure for BAX aneurysms in the interpeduncular and prepontine spaces.

\section{Exposure of Perforators}

The perforators arising from the bilateral $\mathrm{P}_{1}$-PCAs were counted. All the surgical windows available for exposure of the BAX and bilateral PCAs were used, including the supracarotid, opticocarotid, and carotid-oculomotor triangles to ensure accurate perforator count. To facilitate the counting and to avoid ambiguity, the perforators emanating from the basilar tip were attributed to either of the PCAs, and counted as well.

\section{Exposed Length of the Main Arterial Branches}

The main arterial branches at the region of the BAX include the following: 1) the basilar trunk, 2) the ipsilateral and contralateral PCAs, and 3) the ipsilateral and contralateral superior cerebellar arteries (SCAs). The maximum exposed (i.e., visualized) length of each of these arteries was measured from its origin. Regarding the basilar trunk, the exposed length of the artery was measured from its terminal bifurcation to the proximal-most exposed point on the basilar trunk.

\section{Clipping Length of the Main Arterial Branches}

In order to better assess vascular control over the main arterial branches, a straight 5-mm temporary aneurysm clip was placed on the distal-most point of the exposed arteries (proximal-most point for basilar trunk) with the aid of a dedicated bayoneted clip applier. Three attempts were made for "safe" placement of the clip-that is, to avoid damaging or distorting any surrounding structure while maintaining a full view of the clip blades during clip application. Similar to the measurement of the exposed length of each artery, the largest clipping length was recorded for each artery of interest (i.e., PCA, SCA, and proximal basilar artery).

\section{Surgical Area of Exposure}

The surgical area of exposure around the BAX was defined as a hexagon with the following vertices: distal-most visible point on the ipsilateral PCA (A), distal-most visible point on the contralateral PCA (B), distal-most visible point on the ipsilateral SCA (C), distal-most visible point on the contralateral SCA (D), proximal-most visible point on the basilar trunk (E), and the most superior visible point in the interpeduncular fossa, on an imaginary line that was extended from the BAX along the same direction as the basilar trunk (F) (Fig. 1). Using the tip of the navigation probe of the frameless stereotactic navigation system, we recorded the spatial coordinates of these 6 points. The 


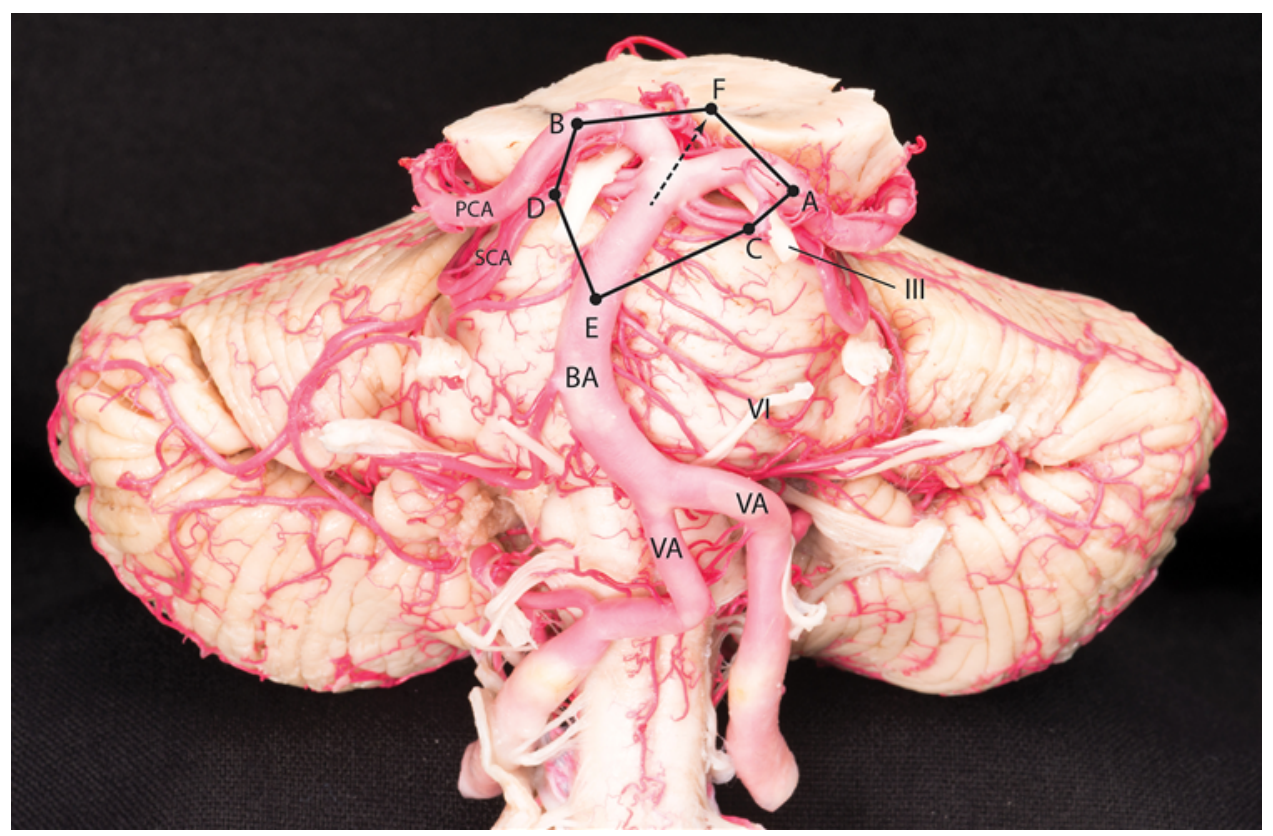

FIG. 1. The hexagonal surgical area of exposure around the BAX shown on a cadaveric specimen. Point $A$, the distal-most visible point on the ipsilateral PCA; point B, the distal-most visible point on the contralateral PCA; point $C$, the distal-most visible point on the ipsilateral SCA; point $D$, the distal-most visible point on the contralateral SCA; point $E$, the proximal-most visible point on the basilar trunk; and point $F$, the most superior visible point in the interpeduncular fossa, on an imaginary line that was extended from the BAX along the same direction as the basilar trunk. BA = basilar artery; VA = vertebral artery; III = oculomotor nerve; $\mathrm{VI}=$ abducent nerve. Copyright Michael T. Lawton. Published with permission. Figure is available in color online only.

area of the reconstructed hexagon was calculated using surface area calculator software (Bitwise Ideas).

\section{Expanded EEA to the BAX}

Endoscopic endonasal surgical simulations were carried out on the same heads using $0^{\circ}$ and $30^{\circ}$ rigid endoscopes (Stryker). Each head was fixed using a 3-pin head clamp (Mizuho America) in the supine position with the neck extended $20^{\circ}$. An endoscopic binostril approach was carried out in all specimens to reach the clivus and the sellar region. The transnasal approach started with bilateral middle turbinectomies and localization of the bilateral sphenopalatine foramina. Next, a posterior septectomy, bilateral posterior ethmoidectomies, and a wide sphenoidotomy were performed to expose the sella. Following identification of the pterygopalatine ganglion, the vidian nerve was skeletonized bilaterally using an endoscopic high-speed drill (Medtronic) to localize the foramen lacerum and paraclival segments of the internal carotid artery (ICA). At this point, the exposed area extends from the planum sphenoidale and tuberculum sellae superiorly to the floor of the sphenoid sinus inferiorly. The clivus, sellar face, tubercular recess, and the posterior half of the planum sphenoidale were drilled to expose the dura. From superior to inferior, the lateral extents of bone drilling included the dura covering the bilateral optic nerves and the parasellar and paraclival segments of the ICA. The retrosellar clivus was drilled as much superiorly as possible, but the area of posterior clinoid processes and upper dorsum sellae were left intact (i.e., the clival bone behind the pituitary gland). Next, the exposed dura of the clivus was opened at midline using an endonasal durotomy knife, and it was excised to expose the ventral surface of the brainstem and adjacent posterior circulation vessels. When extending the dural opening laterally, care was taken to spare the abducent nerve, its dural entrance, and its interdural course. At this stage, the dural coverings of the sella and planum sphenoidale were preserved (Fig. 2). Using the endoscope and the stereotactic navigation system, the same variables described above were measured and recorded through the endoscopic endonasal route. To maintain surgical relevance, the proximal exposure of the basilar artery was measured no further inferior than the take-off of the most superior anterior inferior cerebellar artery. After measuring the first set of endoscopic variables, bilateral pituitary gland transposition (PT) (including bilateral posterior clinoidectomies) was performed as described by Kassam et al., ${ }^{28}$ and variables were measured again (Fig. 2E-H).

\section{Statistical Analysis}

IBM SPSS Statistics version 24.0 (IBM Corp.) was used to perform statistical analysis. One-way ANOVA with Tukey-Kramer post hoc analysis was used to compare independent means between parametric variables. The 2-sample t-test was used to compare means between left and right measurements during individual endoscopic approaches. A p value $<0.05$ was considered to be statistically significant.

\section{Defining the Optimal BAX Height for EEA}

In order to define indications for EEA in cases of BAX 

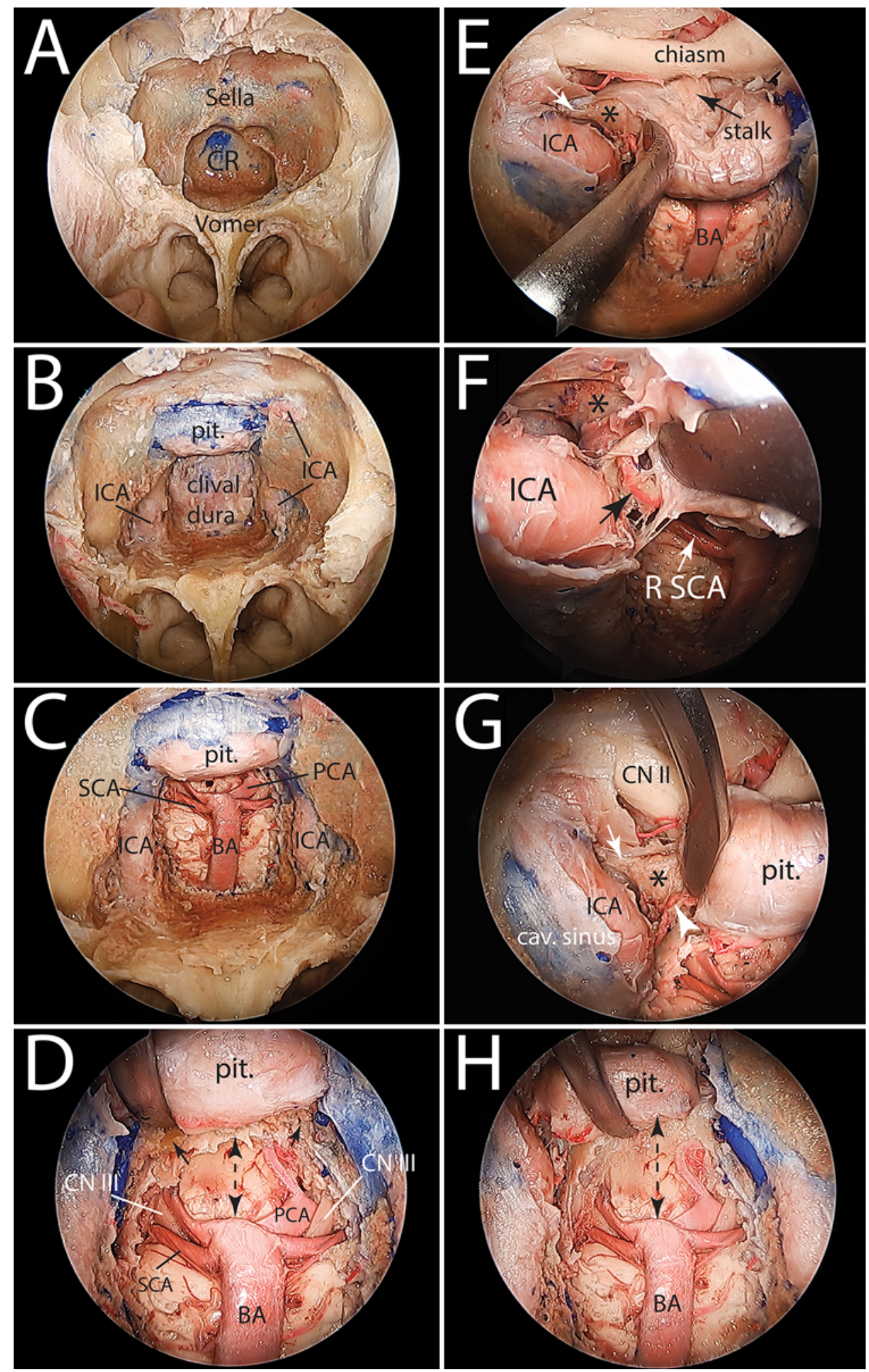

FIG. 2. Stepwise cadaveric dissection demonstrating the EEA to the basilar apex. A: Expanded EEA with bilateral middle turbinectomies, posterior nasal septectomy, and a large sphenoidotomy performed to expose the sella and clival recess. B: Bone drilling of the ventral skull base has been completed from the planum sphenoidale superiorly to the floor of the sphenoid sinus inferiorly. C: Lateral extensions of bone drilling are the paraclival ICAs. The clival dura has been opened and the basilar artery is exposed, as is its terminal quadrifurcation. D: Close-up view of the basilar apex region showing the remaining dorsum sella bone (small black arrows), and the relationship between the basilar apex, the oculomotor nerves, and the floor of the third ventricle. The dashed double-headed arrow shows the space available superior to the basilar apex without a PT. FIG. 2. (continued) $\rightarrow$ 
FIG. 2. E: PT starts with opening the dura of the sellar region and developing the plane between the pituitary capsule medially and the medial dural wall of the cavernous sinus. This exposes the posterior clinoid process (asterisk). Small white arrow marks the attachment of posterior petroclinoid ligament to the posterior clinoid process. F: Magnified view of the image in $\mathrm{E}$ showing the inferior hypophyseal artery originating from the cavernous segment of the ICA (black arrow). This small artery needs to be divided to allow for a full exposure of the posterior clinoid process (asterisk). G: Medial mobilization of the pituitary to expose the inferior hypophyseal artery (white arrowhead), the posterior clinoid process (asterisk), and the posterior petroclinoid ligament attaching to its posterolateral aspect (white arrow). $\mathrm{H}$ : Bilateral transposition of the pituitary is completed with resection of the dorsum sellae and bilateral posterior clinoid processes. Note the increased space available superior to the basilar apex (dashed double-headed arrow) and compare with that shown in D. cav. = cavernous; $\mathrm{CN}=$ cranial nerve; $\mathrm{CR}=$ clival recess; pit. = pituitary; $\mathrm{R}=$ right. Copyright Michael T. Lawton. Published with permission. Figure is available in color online only.

aneurysms, different cutoff points were selected within the range of 25th-75th percentiles of the BAX height. For each endonasal approach (EEA and EEA + PT), the specimens were separated into 2 groups formed based on the assumed cutoff point (one group with BAX height $\leq$ assumed cutoff point and another group with BAX height $>$ assumed cutoff point). The measured variables (exposed and clipping lengths of the arteries, perforator counts, and the surgical area of exposure) were compared between groups to find statistically significant differences (2-sample t-test). The optimal cutoff point was defined as a BAX height for which the groups had maximum difference in various variables as well as the highest frequency of statistically significant differences.

\section{Results}

The average BAX height was $-1.8 \mathrm{~mm}$ (median -4 $\mathrm{mm}$; range $-9.3 \mathrm{~mm}$ to $+6 \mathrm{~mm}$ ). Tables 1 and 2 list the results of the measurements performed. During the orbitozygomatic approach, none of the comparisons between the ipsilateral and contralateral measured values yielded statistically significance differences, except the clipping length of the SCA, which was significantly greater on the ipsilateral side $(\mathrm{p}=0.001)$ (Table 1). A brief description of the comparisons between the approaches follows.

\section{Orbitozygomatic Approach Versus the EEA With and Without PT}

There was no statistically significant difference be-

TABLE 1. Measurements performed on 15 cadaveric heads ( 30 sides) for exposure and vascular control of the basilar apex region through the orbitozygomatic approach

\begin{tabular}{lrcc}
\hline \multicolumn{1}{c}{ Measurement } & Ipsilateral & Contralateral & p Value* \\
\hline No. of counted $\mathrm{P}_{1}$ perforators & $3.9 \pm 2.5$ & $3.0 \pm 1.7$ & 0.6 \\
\hline PCA exposure & $19.7 \pm 4.7$ & $17.9 \pm 6.0$ & 0.64 \\
\hline PCA clipping & $19.2 \pm 5.5$ & $14.3 \pm 5.3$ & 0.001 \\
\hline SCA exposure & $13.8 \pm 3.2$ & $13.2 \pm 3.9$ & 0.94 \\
\hline SCA clipping & $12.6 \pm 3.4$ & $11.0 \pm 3.7$ & 0.36 \\
\hline Proximal basilar exposure & $7.7 \pm 3.6$ & $\mathrm{NA}$ & $\mathrm{NA}$ \\
\hline Proximal basilar clipping & $6.6 \pm 3.1$ & $\mathrm{NA}$ & $\mathrm{NA}$ \\
\hline Surgical area of exposure $\left(\mathrm{cm}^{2}\right)$ & $3.2 \pm 1.7$ & $\mathrm{NA}$ & $\mathrm{NA}$ \\
\hline
\end{tabular}

NA = not applicable.

Values are presented as the mean $\pm \mathrm{SD}$ and are shown in millimeters $(\mathrm{mm})$

unless otherwise stated.

* One-way ANOVA with Tukey-Kramer post hoc analysis. tween counted perforators on the $\mathrm{P}_{1}$-PCAs (ipsilateral or contralateral) during the orbitozygomatic approach and any of the endoscopic approaches (one-way ANOVA, $p=$ 0.08 ) (Table 3, Fig. 3A). The surgical area of exposure with the orbitozygomatic approach was larger than that for the EEA without PT and smaller than that for the EEA with PT (Fig. 3B). However, these differences did not reach statistical significance (one-way ANOVA, $p=0.2$ ). All other comparisons between the orbitozygomatic approach and either of the endoscopic approaches reached statistical significance (Table 3). Except for proximal basilar artery exposure and clipping, the orbitozygomatic approach yielded significantly greater values (for ipsilateral and contralateral PCA and SCA exposure and clipping) compared to both endoscopic approaches (Tables 1 and 2, Fig. 3C-E). On the other hand, proximal basilar artery exposure end clipping lengths were significantly greater with the EEA than those obtained with the orbitozygomatic approach.

TABLE 2. Measurements performed on 15 cadaveric heads ( 30 sides) for exposure and vascular control of the basilar apex region through the endoscopic endonasal transclival approach (with and without pituitary transposition)

\begin{tabular}{lrcc}
\hline \multicolumn{1}{c}{ Approach } & \multicolumn{1}{c}{ Left } & Right & p Value \\
\hline EEA w/o PT & & & \\
\hline No. of counted $\mathrm{P}_{1}$ perforators & $3.0 \pm 2.5$ & $2.7 \pm 2.2$ & 0.2 \\
\hline PCA exposure & $8.6 \pm 4.8$ & $8.6 \pm 4.8$ & 0.48 \\
\hline PCA clipping & $5.4 \pm 4.3$ & $4.3 \pm 2.8$ & 0.21 \\
\hline SCA exposure & $8.2 \pm 3.7$ & $6.8 \pm 3.9$ & 0.16 \\
\hline SCA clipping & $5.7 \pm 3.0$ & $4.2 \pm 2.7$ & 0.08 \\
\hline Proximal basilar exposure & $17.7 \pm 3.9$ & $\mathrm{NA}$ & $\mathrm{NA}$ \\
\hline Proximal basilar clipping & $17.7 \pm 3.9$ & $\mathrm{NA}$ & $\mathrm{NA}$ \\
\hline Surgical area of exposure $\left(\mathrm{cm}^{2}\right)$ & $2.9 \pm 0.8$ & $\mathrm{NA}$ & $\mathrm{NA}$ \\
\hline EEA w/ PT & & & \\
\hline No. of counted $\mathrm{P}_{1}$ perforators & $4.2 \pm 1.7$ & $3.3 \pm 1.8$ & 0.08 \\
\hline PCA exposure & $12 \pm 3.3$ & $11.4 \pm 3.6$ & 0.3 \\
\hline PCA clipping & $9.9 \pm 3.1$ & $8.6 \pm 2.9$ & 0.11 \\
\hline SCA exposure & $9.5 \pm 2.1$ & $8.5 \pm 2.5$ & 0.11 \\
\hline SCA clipping & $6.6 \pm 1.6$ & $5.6 \pm 1.9$ & 0.08 \\
\hline Proximal basilar exposure & $18.3 \pm 3.7$ & $\mathrm{NA}$ & $\mathrm{NA}$ \\
\hline Proximal basilar clipping & $18.3 \pm 3.7$ & $\mathrm{NA}$ & $\mathrm{NA}$ \\
\hline Surgical area of exposure $\left(\mathrm{cm}^{2}\right)$ & $3.8 \pm 1.1$ & $\mathrm{NA}$ & $\mathrm{NA}$ \\
\hline
\end{tabular}

Values are presented as the mean $\pm \mathrm{SD}$ and are shown in millimeters $(\mathrm{mm})$ unless otherwise stated.

* Two-sample t-test. 
TABLE 3. Results of comparisons between the orbitozygomatic approach and the endoscopic endonasal transclival approach without and with PT

\begin{tabular}{lcc}
\hline \multicolumn{1}{c}{ Measurement } & \multicolumn{2}{c}{ p Value $^{*}$} \\
\cline { 2 - 3 } & Ipsilat OZ & Contralat OZ \\
\hline EEA w/o PT & 0.22 & 0.94 \\
\hline No. of counted $\mathrm{P}_{1}$ perforators & $<0.0001$ & $<0.0001$ \\
\hline PCA exposure & $<0.0001$ & $<0.0001$ \\
\hline PCA clipping & $<0.0001$ & $<0.0001$ \\
\hline SCA exposure & $<0.0001$ & $<0.0001$ \\
\hline SCA clipping & $<0.0001$ & $\mathrm{NA}$ \\
\hline Proximal basilar exposure & $<0.0001$ & $\mathrm{NA}$ \\
\hline Proximal basilar clipping & 0.81 & $\mathrm{NA}$ \\
\hline Surgical area of exposure $\left(\mathrm{cm}^{2}\right)$ & & \\
\hline EEA w/ PT & 1.0 & 0.447 \\
\hline No. of counted $\mathrm{P}_{1}$ perforators & $<0.0001$ & $<0.0001$ \\
\hline PCA exposure & $<0.0001$ & 0.007 \\
\hline PCA clipping & $<0.0001$ & $<0.0001$ \\
\hline SCA exposure & $<0.0001$ & $<0.0001$ \\
\hline SCA clipping & $<0.0001$ & $\mathrm{NA}$ \\
\hline Proximal basilar exposure & $<0.0001$ & $\mathrm{NA}$ \\
\hline Proximal basilar clipping & 0.4 & $\mathrm{NA}$ \\
\hline Surgical area of exposure $\left(\mathrm{cm}^{2}\right)$ & & \\
\hline OZ = orbitozygomatic. & & \\
${ }^{2}$ One-way ANOVA with Tukey-Kramer post hoc analysis. & \\
\hline
\end{tabular}

\section{The Impact of Pituitary Transposition}

During the EEA without PT, visualization of bilateral PCAs was usually difficult and frequently required the use of the angled endoscope to optimize visualization. Nevertheless, PCA exposure and control were possible in the majority of specimens $(n=13 / 15)$ during EEA without PT. In 2 specimens with a high-lying BAX, the bilateral PCAs were not optimally visualized, and PCA clipping was impossible in these specimens (Fig. 4). During the EEA with PT, the exposure of the bilateral PCAs was much better than during the EEA without a PT. Within-group comparisons for each of the endoscopic approaches did not show statistically significant differences between left and right measurements (Table 2). There was an increase in all variables after PT (Table 2, Fig. 3). PCA exposure and PCA clipping lengths had statistically significantly greater values during the EEA with PT compared to the EEA without PT ( $p=0.04$ for PCA exposure length; $p=0.001$ for PCA clipping length). However, comparisons between the two endoscopic approaches for other variables did not reach statistically significant differences.

\section{BAX Height and the EEA}

The 25th-75th percentile range for BAX height included $-4.8 \mathrm{~mm}$ to $+2.9 \mathrm{~mm}$ heights. Therefore, with intervals of $1 \mathrm{~mm}$, cutoff points from $-5 \mathrm{~mm}$ to $+3 \mathrm{~mm}$ were tested for each endoscopic approach and comparisons were made (Supplemental Tables 1 and 2). From all cutoff points tested, a BAX height of $-4 \mathrm{~mm}$ was associated with the greatest absolute difference between individual variables and the greatest frequency of statistically significant $p$ values (both for the EEA and EEA + PT). Therefore, the EEA and EEA + PT gave rise to significantly greater values of exposure and clipping lengths of arteries, perforator counts, and surgical area of exposure if the BAX height was $-4 \mathrm{~mm}$ or less (Fig. 5, Supplemental Tables 1 and 2).

\section{Discussion}

Our results show that except for the proximal basilar artery exposure and clipping, the EEA (even when supplemented by a PT) does not offer any other advantage over the orbitozygomatic approach for reaching the BAX region. On the other hand, considering the better exposure of the proximal basilar trunk, the EEA may be a viable option for addressing low-lying BAX lesions and those at the midbasilar trunk.

\section{Comparison Between the Transcranial Approach and EEA}

Our results show that exposure and vascular control of the basilar quadrifurcation are better with the orbitozygomatic approach. Even with the addition of PT, the orbitozygomatic approach provides more robust control over the bilateral PCAs and SCAs (Fig. 3). Although the contralateral exposure and clipping of the PCA were inferior to those of its ipsilateral counterpart during the transcranial exposure, both had averages higher than the two tested EEAs. This observation could be explained by the limiting factor of the bilateral oculomotor nerves and paraclival ICAs blocking the lateral exposure and clipping of the PCAs and SCAs during the EEA. PT increases the aforementioned lengths through provision of a better visualization (and hence safer exposure and greater clipping lengths) (Fig. 4). However, the anatomical location of the oculomotor nerves and ICAs still plays an important role in limiting the control over the most lateral aspects of the PCAs and SCAs during the EEA (Fig. 4).

On the other hand, the EEA (with or without PT) was considerably superior to the transcranial approach in terms of the control over the basilar artery (Fig. 3E). In BAX aneurysm surgery (especially during an intraoperative rupture), control over the basilar artery is probably the most important parameter regarding the so-called proximal control concept, whereas control over the PCAs is less important because the aneurysm is less vigorously filled through backflow from posterior communicating arteries. Controlling the SCAs may be the least important parameter in this regard. In fact, if the surgeon successfully places a temporary clip on the proximal basilar artery, the majority of aneurysm inflow would be shut off. However, considering the less robust control of the BAX quadrifurcation area during EEA, which may be translated into less surgical control over the aneurysm sac, better control over the basilar artery per se may not provide significant advantage for the EEA \pm PT. Nevertheless, with low-lying BAX aneurysms, the EEA may be more advantageous because surgical control becomes progressively better via the EEA when the BAX height goes lower (see "Role of BAX Height").

The total surgical area of exposure could be considered 

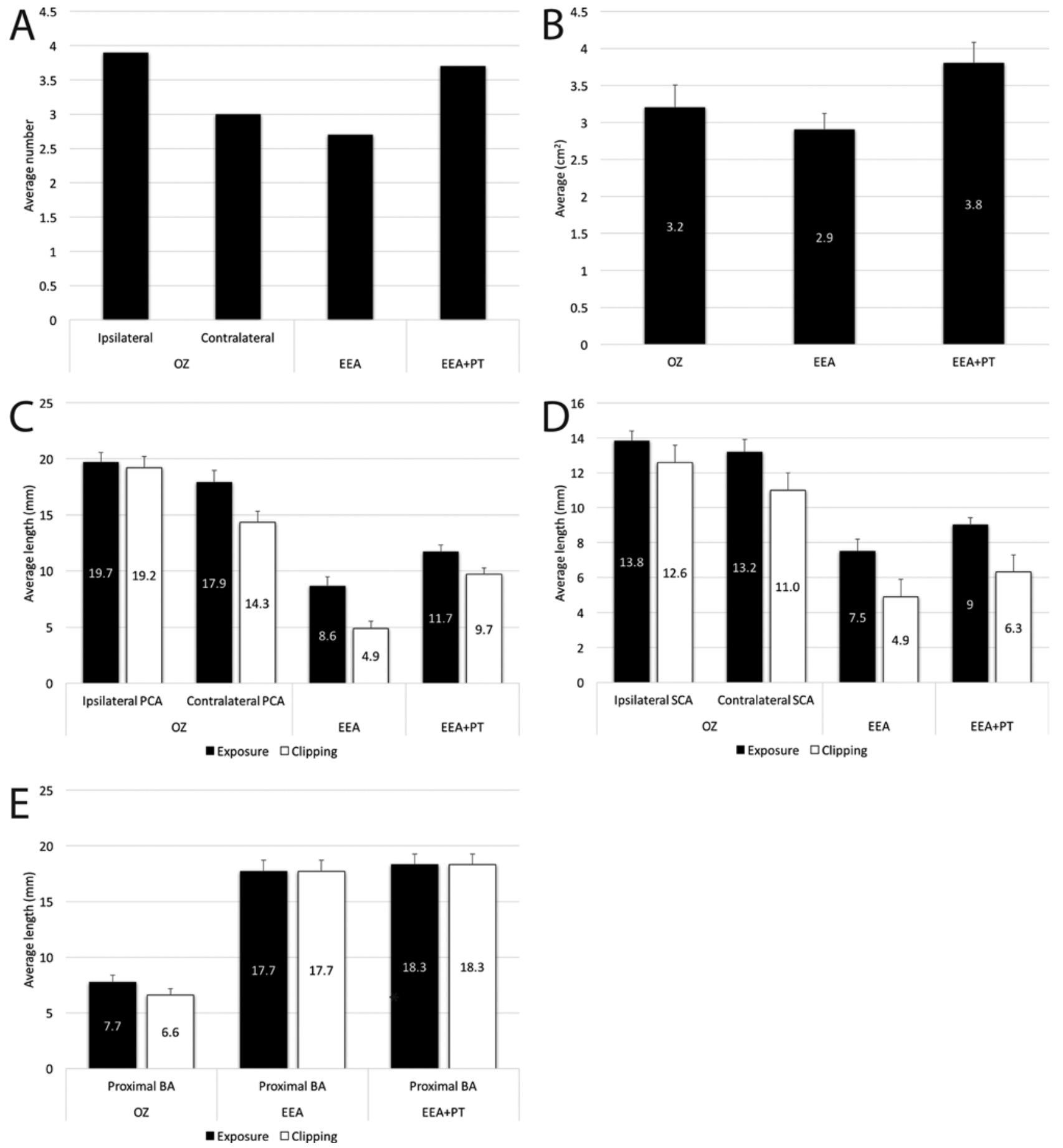

FIG. 3. A: Bar graph illustrating the average number of $\mathrm{P}_{1}$-PCA perforators during the orbitozygomatic approach (ipsilateral and contralateral $\mathrm{P}_{1}$ ) and EEA with and without PT. Please note that for endonasal approaches, the overall average, including left and right sides, is presented. B: Bar graph illustrating the average surgical area of exposure at the region of basilar apex provided by the orbitozygomatic approach and the EEAs with and without PT. Please see Fig. 2 for an illustration of the surgical area of exposure around the basilar apex. C-E: Exposure and clipping lengths of the vessels of the basilar apex region. C: PCA; D: SCA; and E: basilar artery. Error bars represent the standard errors. $\mathrm{OZ}=$ orbitozygomatic.

as the area the surgeon has general visual (and maneuvering) control of during the surgery. This is important because when the surgical target lies in a significantly larger area of exposure, the surgeon may be able to have better control over the field. This fact is especially important with aneurysms when an intraoperative rupture happens. A larger surgical area may allow for easier intraoperative aneurysm rupture control. Although the EEA with PT 

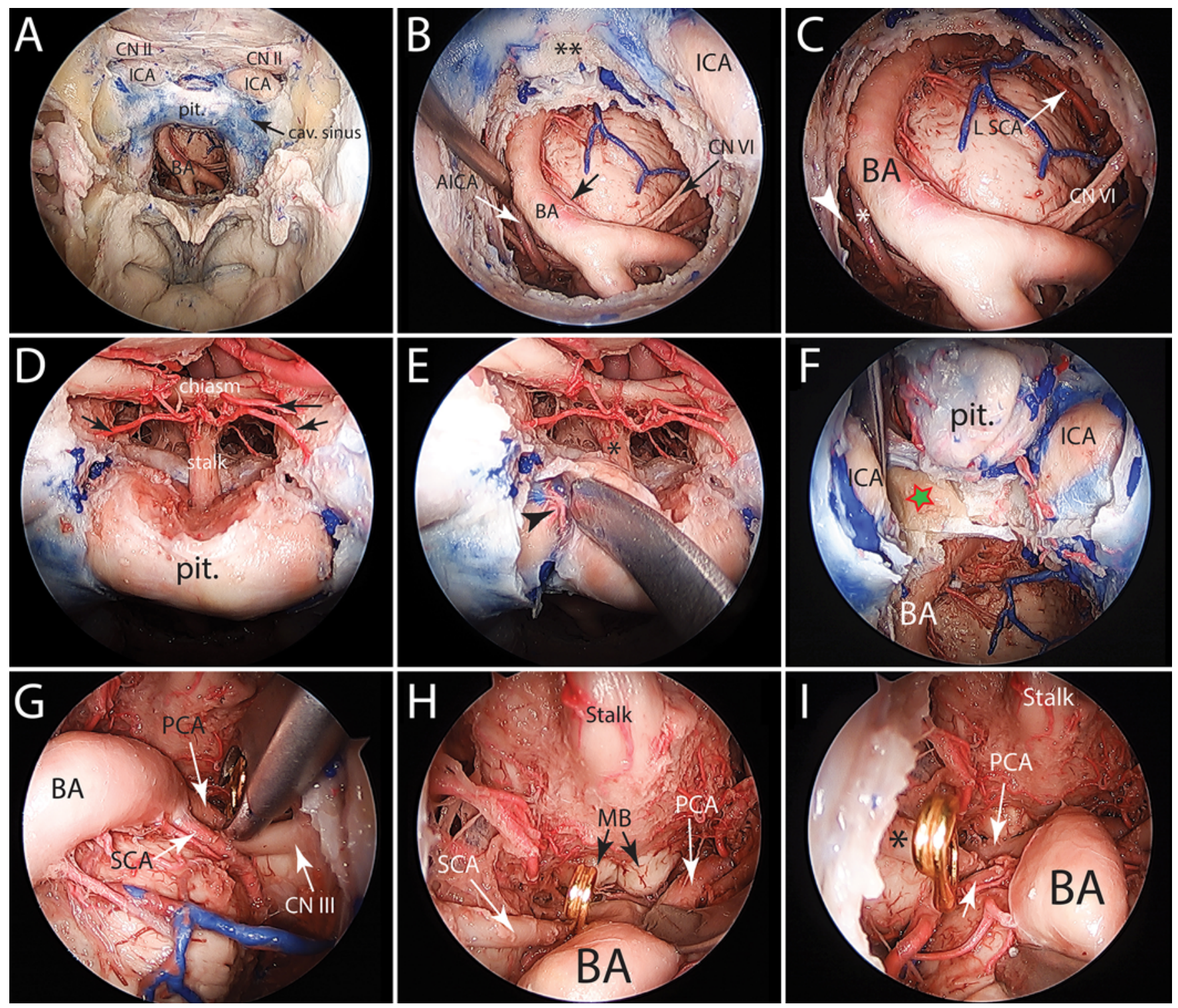

FIG. 4. Cadaveric endoscopic endonasal exposure of the basilar trunk showing the exposure of a retrosellar basilar apex before and after a PT. A: Expanded endonasal exposure of the ventral skull base from the planum sphenoidale to the floor of the sphenoid sinus. The clival dura had been opened to expose the basilar artery and ventral brainstem. B: Close-up view of the image in A showing the basilar trunk deviated to the right side. Note the origin of the anterior inferior cerebellar arteries (small white and black arrows). Also, note that the bone of the retrosellar area (i.e., dorsum sellae and posterior clinoid processes) is left undrilled (double asterisks). C: A $30^{\circ}$ angled endoscope is used to visualize the basilar apex. However, the sella and the retrosellar bone do not allow optimal visualization of the basilar apex and only the left SCA is visible. Please note the right anterior inferior cerebellar artery (asterisk) and the right abducent nerve (white arrowhead). D: In preparation for a pituitary transposition, the dura of the sellar and tuberculum sella region is opened to expose the pituitary stalk and upper surface of the pituitary gland. Arrows designate the superior hypophyseal arteries. E: The plane between the pituitary capsule and medial wall of the cavernous sinus is developed, exposing the inferior hypophyseal artery (arrowhead). Care is taken to minimally distort the pituitary stalk (asterisk) (dissection is shown on the right side only). F: Medial mobilization of the pituitary gland exposes the upper dorsum sella and posterior clinoid process (star). G-I: Following a complete bilateral PT and bilateral posterior clinoidectomy and dorsectomy, the basilar apex region and the floor of the third ventricle are completely exposed ( $30^{\circ}$ angled endoscope used). Asterisk shows the right oculomotor nerve. Clipping of the left PCA $(G)$, right PCA $(H)$, and right SCA $(I)$ is shown. AICA = anterior inferior cerebellar artery; $M B=$ mammillary body. Copyright Michael T. Lawton. Published with permission. Figure is available in color online only.

provided a larger surgical area compared to the orbitozygomatic approach, the difference did not reach statistical significance (Tukey-Kramer post hoc analysis, $\mathrm{p}=$ 0.4). Furthermore, considering the suboptimal exposure and control over the BAX quadrifurcation (even with PT) compared with the orbitozygomatic approach, the marginal advantage of a greater surgical area would not have much clinical significance. 

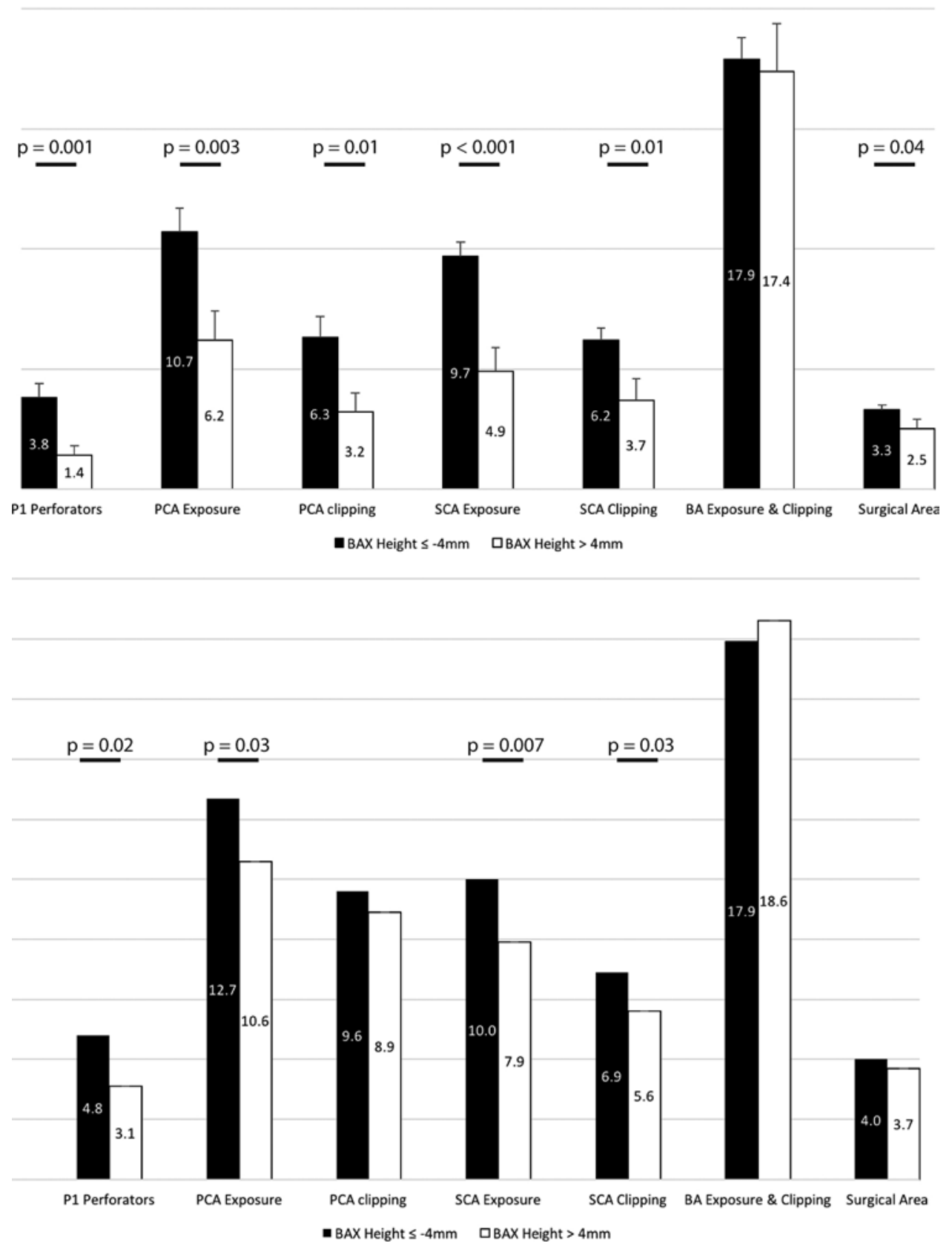

FIG. 5. Bar graphs showing comparisons between different measured variables using a cutoff point of $-4 \mathrm{~mm}$ for the basilar apex height. At this cutoff point, the differences between variables in 2 groups were maximal and with most frequent statistically significant differences (compared to other cutoff points). Upper: Graph showing the analysis for EEA without PT. Lower: Graph showing the analysis for EEA with PT. Statistically significant comparisons are shown with horizontal bars as well as p values for 2-sample t-test. Please see text and Supplemental Tables 1 and 2 for further information.

\section{Impact of PT in EEAs for Basilar Apex Aneurysms}

Even with the use of an angled endoscope, the EEA without PT provided suboptimal exposure of bilateral PCAs in 2 specimens, which rendered PCA clipping unfeasible. This is a major limitation of the EEA to the BAX region, which has been mentioned previously, yet not objectively shown. ${ }^{31,32,41}$ The addition of PT led to an increase in all measured variables (Fig. 3). However, none of these increases reached statistical significance, except the clip- ping and exposure lengths of the bilateral PCAs. Also, clipping became feasible in 2 specimens in which clipping was not possible during EEA without PT. On the other hand, the EEA without PT was as good as EEA with PT in exposing and clipping of the SCAs and proximal basilar artery. These differences show that as the surgical target ascends along the basilar trunk, the advantage of EEA diminishes and vice versa. Considering the superiority of the EEA to the orbitozygomatic approach in controlling 
the basilar trunk, one may conclude that the EEA without $\mathrm{PT}$ is a viable option for low-lying BAX and midbasilar aneurysms..$^{10,31,41}$

\section{Role of BAX Height}

The BAX is considered "normal" when it lies within 5 $\mathrm{mm}$ of the sagittal level of the dorsum sellae. ${ }^{21}$ With lowlying BAX aneurysms, the exposure and maneuverability gained through the transcranial approaches become significantly diminished. ${ }^{15,29}$ The majority of BAXs observed in this study $(\mathrm{n}=11 / 15)$ were of normal type (average BAX height $-1.8 \mathrm{~mm}$ ); however, with a so-called normal BAX (lying directly behind the sella), the pituitary gland may still hinder optimal exposure and vascular control of the PCAs. According to our results, the EEA without PT is considerably inferior to the EEA with PT regarding control and exposure of the PCAs, which is an essential requisite for BAX aneurysm surgery. Therefore, it is conceivable that to effectively approach a BAX aneurysm through the EEA, PT would often be necessary. This finding is in keeping with previous recommendations. ${ }^{19}$ However, PT may be a difficult technique to perform, and it carries clinical risks. The delicate tissue plane between the pituitary gland capsule and the medial cavernous sinus wall should be developed to completely expose the dorsum sellae and the posterior clinoid process (Figs. 2 and 4). In addition to the risk of ICA injury, ${ }^{18,24}$ the inferior hypophyseal artery (when present) needs to be divided to allow complete unilateral transposition. ${ }^{28}$ This may cause postoperative panhypopituitarism. In our cadaveric surgical simulations, the addition of unilateral PT did not optimize surgical exposure. Therefore, we performed bilateral PTs to maximize the BAX exposure and control. However, bilateral PT even carries a higher risk for postoperative panhypopituitarism. ${ }^{14,28,31}$ Therefore, the gains of EEA with PT should be weighed against its possible complications when this approach is considered for the treatment of BAX aneurysms.

On the other hand, our analyses showed that, with the BAX height lower than $-4 \mathrm{~mm}$, the EEA (with or without PT) provides significantly greater values compared to BAXs at higher positions (Supplemental Tables 1 and 2, Fig. 5). Therefore, the EEA (without PT) may provide optimal control over a BAX aneurysm lying $\geq 4 \mathrm{~mm}$ inferior to dorsum sellae or at the midbasilar artery. In such cases, the EEA may be a favorable alternative to transcranial approaches to these targets, while avoiding the complications of PT (Fig. 2)..$^{10,31}$ Nevertheless, our results regarding the definition of a cutoff point for BAX height to help with approach selection should be interpreted with caution. The sample size of the present study may not be large enough to draw firm conclusions in this regard. Additionally, if a BAX of $-4 \mathrm{~mm}$ in height still lies behind the pituitary gland, the EEA (even with a PT) may be suboptimal regarding aneurysm exposure and surgical maneuverability. Further clinical studies are warranted for a deeper insight into this issue.

\section{Limitations of the EEA}

Apart from anatomical limitations of the EEA in approaching BAX aneurysms, several technical limitations have been described before. ${ }^{6,24,32}$ Bleeding from the basi- lar venous plexus during dural opening could be troublesome, and optimal hemostasis should be obtained before dural opening. ${ }^{10,41}$ The importance of applying measures to prevent CSF leak cannot be overemphasized (including designing low-profile aneurysm clips that do not interfere with dural reconstruction). ${ }^{24,32,41}$ General rules of cerebrovascular surgery (sharp arachnoid dissection, bimanual dissection, and proximal and distal vascular control) should also be followed during the EEA for treatment of aneurysms. ${ }^{10,19,24}$ Efficient techniques need to be developed and learned for fast and effective control of an intraoperative aneurysm rupture. ${ }^{26,43}$ Special endonasal instruments should be designed and used for endoscopic aneurysm surgery. ${ }^{8,41}$ Finally, the surgeon should have extensive experience with the EEA before attempting to treat a cerebral aneurysm with this technique. $19,27,40$

Overall, the EEA for BAX or mid-basilar trunk aneurysm clipping may be a viable alternative in highly selected cases..$^{19}$ The EEA to the BAX region is not a minimally invasive surgery. ${ }^{19,31}$ Therefore, as shown by the results of the present study, selection of the EEA should be based mainly on the location of the aneurysm on the basilar artery and its relationship with the sella. When appropriately selected, the EEA could provide benefits of proper vascular control, large area of exposure, absence of brain retraction, and potentially a more comfortable postoperative recovery. ${ }^{10,12,17,19,27}$ However, the choice of the EEA must be weighed not only against the traditional transcranial exposures for basilar artery aneurysms, but also against endovascular approaches. Novel endovascular devices and their increasing efficacy with this lesion may diminish the indications for the EEA.

\section{Conclusions}

The results of this study show that the EEA does not offer a superior option compared to the orbitozygomatic approach for accessing the BAX region. However, the EEA to a low-lying BAX or mid-basilar trunk aneurysm can usually be performed without a need for PT. When selected prudently (i.e., in cases involving an aneurysm lying $\geq$ $4 \mathrm{~mm}$ inferior to the dorsum sellae), such lesions may be favorable targets for an EEA in comparison to transcranial approaches that may provide a suboptimal exposure. Further clinical studies are needed to delineate the clinical aspects of this therapeutic challenge.

\section{References}

1. Benet A, Rincon-Torroella J, Lawton MT, González Sánchez JJ: Novel embalming solution for neurosurgical simulation in cadavers. J Neurosurg 120:1229-1237, 2014

2. Bohnstedt BN, Ziemba-Davis M, Sethia R, Payner TD, DeNardo A, Scott J, et al: Comparison of endovascular and microsurgical management of 208 basilar apex aneurysms. J Neurosurg 127:1342-1352, 2017

3. Cavallo LM, Frank G, Cappabianca P, Solari D, Mazzatenta D, Villa A, et al: The endoscopic endonasal approach for the management of craniopharyngiomas: a series of 103 patients. J Neurosurg 121:100-113, 2014

4. Cavallo LM, Messina A, Cappabianca P, Esposito F, de Divitiis E, Gardner P, et al: Endoscopic endonasal surgery of the midline skull base: anatomical study and clinical considerations. Neurosurg Focus 19(1):E2, 2005 
5. Day JD, Giannotta SL, Fukushima T: Extradural temporopolar approach to lesions of the upper basilar artery and infrachiasmatic region. J Neurosurg 81:230-235, 1994

6. Dehdashti AR, Ganna A, Witterick I, Gentili F: Expanded endoscopic endonasal approach for anterior cranial base and suprasellar lesions: indications and limitations. Neurosurgery 64:677-689, 2009

7. Di Somma A, de Notaris M, Stagno V, Serra L, Enseñat J, Alobid I, et al: Extended endoscopic endonasal approaches for cerebral aneurysms: anatomical, virtual reality and morphometric study. BioMed Res Int 2014:703792, 2014

8. Doan V, Lemos-Rodriguez AM, Sreenath SB, Unnithan A, Recinos PF, Zanation AM, et al: Using the endoscopic endonasal transclival approach to access aneurysms arising from AICA, PICA, and vertebral artery: an anatomical study. J Neurol Surg B Skull Base 77:207-211, 2016

9. Drake CG: Surgical treatment of ruptured aneurysms of the basilar artery. Experience with 14 cases. J Neurosurg 23:457-473, 1965

10. Drazin D, Zhuang L, Schievink WI, Mamelak AN: Expanded endonasal approach for the clipping of a ruptured basilar aneurysm and feeding artery to a cerebellar arteriovenous malformation. J Clin Neurosci 19:144-148, 2012

11. Dusick JR, Esposito F, Kelly DF, Cohan P, DeSalles A, Becker DP, et al: The extended direct endonasal transsphenoidal approach for nonadenomatous suprasellar tumors. J Neurosurg 102:832-841, 2005

12. Eloy JA, Carai A, Patel AB, Genden EM, Bederson JB: Combined endoscope-assisted transclival clipping and endovascular stenting of a basilar trunk aneurysm: case report. Neurosurgery 62 (3 Suppl 1):142-144, 2008

13. Enseñat J, Alobid I, de Notaris M, Sanchez M, Valero R, Prats-Galino A, et al: Endoscopic endonasal clipping of a ruptured vertebral-posterior inferior cerebellar artery aneurysm: technical case report. Neurosurgery 69 (1 Suppl Operative):E121-E128, 2011

14. Fernandez-Miranda JC, Gardner PA, Rastelli MM Jr, PerisCelda M, Koutourousiou M, Peace D, et al: Endoscopic endonasal transcavernous posterior clinoidectomy with interdural pituitary transposition. J Neurosurg 121:91-99, 2014

15. Figueiredo EG, Tavares WM, Rhoton AL Jr, de Oliveira E: Nuances and technique of the pretemporal transcavernous approach to treat low-lying basilar artery aneurysms. Neurosurg Rev 33:129-135, 2010

16. Frank G, Sciarretta V, Calbucci F, Farneti G, Mazzatenta D, Pasquini E: The endoscopic transnasal transsphenoidal approach for the treatment of cranial base chordomas and chondrosarcomas. Neurosurgery 59 (1 Suppl 1): ONS50-ONS57, 2006

17. Froelich S, Cebula H, Debry C, Boyer P: Anterior communicating artery aneurysm clipped via an endoscopic endonasal approach: technical note. Neurosurgery 68 (2 Suppl Operative):310-316, 2011

18. Gardner PA, Tormenti MJ, Pant H, Fernandez-Miranda JC, Snyderman CH, Horowitz MB: Carotid artery injury during endoscopic endonasal skull base surgery: incidence and outcomes. Neurosurgery 73 (2 Suppl Operative):ons261ons 270,2013

19. Gardner PA, Vaz-Guimaraes F, Jankowitz B, Koutourousiou M, Fernandez-Miranda JC, Wang EW, et al: Endoscopic endonasal clipping of intracranial aneurysms: surgical technique and results. World Neurosurg 84:1380-1393, 2015

20. Ge H, Lv X, Jin H, Tian Z, Li Y, He H: The role of endovascular treatment in unruptured basilar tip aneurysms. Interv Neuroradiol 23:8-13, 2017

21. Gonzalez LF, Amin-Hanjani S, Bambakidis NC, Spetzler RF: Skull base approaches to the basilar artery. Neurosurg Focus 19(2):E3, 2005

22. Hadad G, Bassagasteguy L, Carrau RL, Mataza JC, Kassam
A, Snyderman $\mathrm{CH}$, et al: A novel reconstructive technique after endoscopic expanded endonasal approaches: vascular pedicle nasoseptal flap. Laryngoscope 116:1882-1886, 2006

23. Harvey RJ, Nogueira JF, Schlosser RJ, Patel SJ, Vellutini E, Stamm AC: Closure of large skull base defects after endoscopic transnasal craniotomy. Clinical article. J Neurosurg 111:371-379, 2009

24. Heiferman DM, Somasundaram A, Alvarado AJ, Zanation AM, Pittman AL, Germanwala AV: The endonasal approach for treatment of cerebral aneurysms: a critical review of the literature. Clin Neurol Neurosurg 134:91-97, 2015

25. Heros RC, Lee SH: The combined pterional/anterior temporal approach for aneurysms of the upper basilar complex: technical report. Neurosurgery 33:244-251, 1993

26. Kassam A, Snyderman CH, Carrau RL, Gardner P, Mintz A: Endoneurosurgical hemostasis techniques: lessons learned from 400 cases. Neurosurg Focus 19(1):E7, 2005

27. Kassam AB, Mintz AH, Gardner PA, Horowitz MB, Carrau $\mathrm{RL}$, Snyderman CH: The expanded endonasal approach for an endoscopic transnasal clipping and aneurysmorrhaphy of a large vertebral artery aneurysm: technical case report. Neurosurgery 59 (1 Suppl 1):E162-E165, 2006

28. Kassam AB, Prevedello DM, Thomas A, Gardner P, Mintz A, Snyderman C, et al: Endoscopic endonasal pituitary transposition for a transdorsum sellae approach to the interpeduncular cistern. Neurosurgery 62 (3 Suppl 1):57-74, 2008

29. Kim YD, Elhadi AM, Mendes GA, Maramreddy N, Agrawal A, Kalb S, et al: Quantitative study of the opticocarotid and carotid-oculomotor windows for the interpeduncular fossa, before and after internal carotid artery mobilization and posterior communicating division. Neurosurgery 11 (Suppl 2):162-180, 2015

30. Krisht AF, Krayenbühl N, Sercl D, Bikmaz K, Kadri PA: Results of microsurgical clipping of 50 high complexity basilar apex aneurysms. Neurosurgery 60:242-252, 2007

31. Labib M, Dehdashti AR: Extended endoscopic endonasal transclival clipping of posterior circulation aneurysms - an alternative to the transcranial approach. Acta Neurochir (Wien) 157:2087-2088, 2015

32. Lai LT, Morgan MK, Dalgorf D, Bokhari A, Sacks PL, Sacks $\mathrm{R}$, et al: Cadaveric study of the endoscopic endonasal transtubercular approach to the anterior communicating artery complex. J Clin Neurosci 21:827-832, 2014

33. Lawton MT: Basilar apex aneurysms: surgical results and perspectives from an initial experience. Neurosurgery 50:110,2002

34. Lemos-Rodríguez AM, Sreenath S, Unnithan A, Doan V, Recinos PF, Zanation A, et al: A new window for the treatment of posterior cerebral artery, superior cerebellar artery, and basilar apex aneurysm: the expanded endoscopic endonasal approach. J Neurol Surg B Skull Base 77:308-313, 2016

35. Nanda A, Sonig A, Banerjee AD, Javalkar VK: Microsurgical management of basilar artery apex aneurysms: a single surgeon's experience from Louisiana State University, Shreveport. World Neurosurg 82:118-129, 2014

36. Pandey AS, Koebbe C, Rosenwasser RH, Veznedaroglu E: Endovascular coil embolization of ruptured and unruptured posterior circulation aneurysms: review of a 10-year experience. Neurosurgery 60:626-637, 2007

37. Sanai N, Tarapore P, Lee AC, Lawton MT: The current role of microsurgery for posterior circulation aneurysms: a selective approach in the endovascular era. Neurosurgery 62:1236-1253, 2008

38. Sanmillan JL, Lawton MT, Rincon-Torroella J, El-Sayed IH, Zhang X, Meybodi AT, et al: Assessment of the endoscopic endonasal transclival approach for surgical clipping of anterior pontine AICA aneurysms. World Neurosurg 89:368-375, 2016

39. Sano H, Kato Y, Akashi K, Yamaguchi S, Hayakawa M, 
Arunkumar R, et al: Operation on high-lying basilar bifurcation aneurysms. Surg Neurol 48:458-464, 1997

40. Snyderman CH, Fernandez-Miranda J, Gardner PA: Training in neurorhinology: the impact of case volume on the learning curve. Otolaryngol Clin North Am 44:1223-1228, 2011

41. Somanna S, Babu RA, Srinivas D, Narasinga Rao KV, Vazhayil V: Extended endoscopic endonasal transclival clipping of posterior circulation aneurysms - an alternative to the transcranial approach. Acta Neurochir (Wien) 157:20772085,2015

42. Szentirmai O, Hong Y, Mascarenhas L, Salek AA, Stieg PE, Anand VK, et al: Endoscopic endonasal clip ligation of cerebral aneurysms: an anatomical feasibility study and future directions. J Neurosurg 124:463-468, 2016

43. Valentine R, Wormald PJ: A vascular catastrophe during endonasal surgery: an endoscopic sheep model. Skull Base 21:109-114, 2011

44. Yasargil MG, Antic J, Laciga R, Jain KK, Hodosh RM, Smith RD: Microsurgical pterional approach to aneurysms of the basilar bifurcation. Surg Neurol 6:83-91, 1976

45. Zanation AM, Carrau RL, Snyderman CH, Germanwala AV, Gardner PA, Prevedello DM, et al: Nasoseptal flap reconstruction of high flow intraoperative cerebral spinal fluid leaks during endoscopic skull base surgery. Am J Rhinol Allergy 23:518-521, 2009

\section{Disclosures}

The authors report no conflict of interest concerning the materials or methods used in this study or the findings specified in this paper.

\section{Author Contributions}

Conception and design: Tayebi Meybodi, Benet. Acquisition of data: Tayebi Meybodi, Vigo, Rodriguez Rubio, Mokhtari, Kakaizada. Analysis and interpretation of data: Lawton, Tayebi Meybodi, Vigo, Yousef, Mokhtari. Drafting the article: Tayebi Meybodi, Vigo, Dones, Kakaizada. Critically revising the article: Lawton, Tayebi Meybodi, Benet, Vigo, Rodriguez Rubio, Dones. Reviewed submitted version of manuscript: Lawton, Tayebi Meybodi, Benet, Vigo, Rodriguez Rubio, Yousef, Mokhtari, Dones. Approved the final version of the manuscript on behalf of all authors: Lawton. Statistical analysis: Tayebi Meybodi, Vigo, Yousef, Mokhtari. Administrative/technical/material support: Lawton, Benet. Study supervision: Lawton, Benet.

\section{Supplemental Information}

\section{Online-Only Content}

Supplemental material is available with the online version of the article.

Supplemental Tables 1 and 2. https://thejns.org/doi/suppl/10. 3171/2018.1.JNS172813.

\section{Correspondence}

Michael T. Lawton: Barrow Neurological Institute, Phoenix, AZ. michael.lawton@barrowbrainandspine.com. 